\title{
Optimizing the Extraction of Dietary Fibers from Sorghum Bran Using Response Surface Methodology
}

\author{
Ange-Patrice Takoudjou Miafo, ${ }^{1,2}$ Benoît Bargui Koubala, ${ }^{2,3}$ Germain Kansci, ${ }^{1}$ \\ Brice Ulrich Foudjo Saha, ${ }^{1}$ and Elie Fokou ${ }^{1}$ \\ ${ }^{1}$ Department of Biochemistry, Faculty of Science, University of Yaounde I, P.O. Box 812, Yaounde, Cameroon \\ ${ }^{2}$ Department of Life and Earth Sciences, Higher Teachers' Training College, University of Maroua, P.O. Box 55, Maroua, Cameroon \\ ${ }^{3}$ Department of Chemistry, Faculty of Science, University of Maroua, P.O. Box 814, Maroua, Cameroon \\ Correspondence should be addressed to Benoît Bargui Koubala; bkoubala@yahoo.fr
}

Received 5 August 2015; Revised 12 September 2015; Accepted 17 September 2015

Academic Editor: Xuetong Fan

Copyright (C) 2015 Ange-Patrice Takoudjou Miafo et al. This is an open access article distributed under the Creative Commons Attribution License, which permits unrestricted use, distribution, and reproduction in any medium, provided the original work is properly cited.

\begin{abstract}
Response surface methodology was used to optimize the processing parameters of the fiber extraction from sorghum bran. The studied independent factors were ethanol/bran ratio, time, temperature, and number of treatment cycles. A three-level four-variable Box-Behnken design (BBD) was used to establish the optimum conditions of extraction. The results showed that the experimental data could be fitted to a second-order polynomial equation using multiple regression analysis and the model was highly significant $(P<0.0001)$. The optimum extraction conditions were $11.8 \mathrm{~mL} \cdot \mathrm{g}^{-1}$ of ethanol/bran ratio, $60 \mathrm{~min}, 65^{\circ} \mathrm{C}$, and 7 extraction cycles. The experimental yield was $35.52 \%$ which is close to the value predicted by the BBD model (34.36\%). By applying the two combinations of factors generated by the path of steepest descent, the first combination $\left(12 \mathrm{~mL} / \mathrm{g}, 60 \mathrm{~min}, 65^{\circ} \mathrm{C}\right.$, and 8 cycles $)$ allowed a yield of $35.50 \%$, while the second ( $11 \mathrm{~mL} / \mathrm{g}, 70 \mathrm{~min}, 55^{\circ} \mathrm{C}$, and 8 cycles) exhibited a yield of $39.90 \%$ which is higher than that from the $\mathrm{BBD}$ model $(P<0.05)$. Compared to the first combination generated by the path of steepest descent, the BBD model conditions were economical with small number of cycles and low ethanol/bran ratio.
\end{abstract}

\section{Introduction}

The role of dietary fiber (DF) in nutrition and health is well established [1-3]. The beneficial effects of high dietary fiber meals toward the prevention of chronic diseases such as coronary heart disease, obesity, colon cancer, and diabetes [4, 5], as well as the inclusion of DF supplements in slimming diets, have led to the development of a large and profitable market for DF-rich products. Products offered to the consumer include traditional foods (meat, dairy products, breakfast cereals, biscuits, breads, etc.) enriched with different amounts of fiber from various sources. A daily intake of $25-35 \mathrm{~g}$ is encouraged to promote health benefits associated with fiber [6]. However, fiber intake is commonly lower than recommended; therefore development of foods with high fiber content is desirable and the search for available low-cost sources of fiber is essential.
Cereal bran is a rich and common source of dietary fiber [7]. Sorghum is the second most produced cereal in Africa and the 20 million tonnes of sorghum/annum represents onethird of the world crop [8]. The processing of sorghum grains to flour used in a wide variety of attractive and nutritious traditional foods [9] leads to sorghum bran. Part of this byproduct is used for animal feed and the rest is neglected and released a like waste in the environment. Possible adverse environmental effects include inhibition of the crop, ground water pollution, excessive run-off, and air pollution in the form of foul odours [10] and bran particles.

Sorghum bran has high levels of phytochemicals, including proanthocyanidins [11], anthocyanins [12], 3deoxyanthocyanins [13], phenolic acids [14], phytosterols [15], policosanols [16], and dietary fiber [17]. The dietary fiber contents represent about 38 to $45 \%$ of the brans, about 4-6 times the levels measured in the grains [11]. 
Rooney et al. [17]. reported that sorghum bran fractions contained on average 36-50\% total dietary fiber and 35-48\% insoluble dietary fiber on a dry-weight basis. These sorghum bran fractions are potentially useful ingredients in various functional food applications and were shown to produce desirable attributes (e.g., attractive natural color) without adversely affecting other sensory properties of foods such as breads, cookies, and expanded snacks [18, 19]. Rudiger [20] also showed that, at the same percentages, bread fortified with 15\% high-tannin sorghum bran contained higher phenols, antioxidant activity, and fiber than that fortified with flax seed and barley flour. Sorghum fibers are bound to play a crucial role in food applications given the increasing need for diversified functional foods. However, to improve functional foods production and providing added value to sorghum byproducts, fiber must be separated from sorghum bran.

Response surface methodology (RSM) when applied to optimizing conditions in food and pharmaceutical research is an effective tool for optimizing extraction processes [21, 22]. As one type of RSM, Box-Behnken design (BBD) is popularly used, principally to optimize technical parameters. $\mathrm{BBD}$ is more common than other approaches in optimizing processes, such as saving materials, decreasing expenses, and reducing time [23]. It reduces the number of experimental trials needed to evaluate multiple parameters and their interactions.

Research has been carried out on alkali-extracted glucuronoarabinoxylan populations from water-unextractable cell wall material from sorghum in order to assess their structures [24-26]. Similar works were performed to assess the structural features of the xylans present in cereal byproducts such as wheat bran, brewery's spent grain, and corn cobs [27]. Studies have also been conducted showing that whole sorghum bran is a good source of dietary fiber [11, 17, 18], but no investigation has been done on the extraction of this fiber. Therefore, the purpose of the study was to employ a Box-Behnken design to optimize the extraction yield of fibers from sorghum bran.

\section{Materials and Methods}

2.1. Sampling and Extraction of Sorghum Bran Fibers. Grains of Sorghum bicolor (L.) red sorghum were bought from farmers (Far North, Cameroon). These grains were cleaned to remove chaff and dried at $50^{\circ} \mathrm{C}$ (air convection oven, Memmert) for 48 hours. Bran was obtained from cleaned sorghum by pericarp decortication (PRL Dehuller, Nutana Machine Co., Saskatoon, Canada) processes. The bran was dried at $50^{\circ} \mathrm{C}$ for 48 hours (water content of $10.07 \%$ ) and then vacuum-packed in polyethylene bags and kept dry in desiccators prior to experimentation.

For fiber extraction, $5 \mathrm{~g}\left(W_{i}\right)$ of dried bran was soaked in $50 \mathrm{~mL}$ of deionised water for $12 \mathrm{~h}$. The bran was blanched at $95^{\circ} \mathrm{C}$ for $5 \mathrm{~min}$ and filtered. Fibers were obtained by treating the bleached residue in $85 \%$ ethanol with a defined ethanol/residue ratio at fixed time and temperature on a magnetic stirrer (IKAC MAC HS7). The mixture was filtered
TABLE 1: Independent variables and their levels used for BBD.

\begin{tabular}{lcccc}
\hline Coded values & Cycles & $\begin{array}{c}\text { Ratio } \\
(\mathrm{mL} / \mathrm{g})\end{array}$ & $\begin{array}{c}\text { Time } \\
(\mathrm{min})\end{array}$ & $\begin{array}{c}\text { Temperature } \\
\left({ }^{\circ} \mathrm{C}\right)\end{array}$ \\
\hline-1 & 5 & 10 & 40 & 45 \\
0 & 6 & 11 & 50 & 55 \\
+1 & 7 & 12 & 60 & 65 \\
\hline
\end{tabular}

and the residue was recovered to undergo several other treatment cycles. The final residue was then sequentially rinsed with $95 \%$ ethanol and acetone before drying in an oven at $50^{\circ} \mathrm{C}$ for $24 \mathrm{~h}$ [28]. The dried product $\left(W_{f}\right)$ represents the fibers from bran. The yield of fibers $(Y)$ was calculated on the dry weight basis using the following formula:

$$
Y(\%)=\frac{W_{f}(\mathrm{~g})}{W_{i}(\mathrm{~g})} \times 100 .
$$

The multiple leaching processes using ethanol allowed gradual removal of nonfibrous compounds from the bran and thus enriching the residue in fibers and then decreasing of the yield.

\subsection{Experimental Design}

2.2.1. Single-Factor Experimental Design. Single-factor experimental designs were firstly used to define the optimum region representing the set of study areas of independent variables. The four variables were numbers of extracting cycles, ratio of ethanol to bran, time, and temperature.

For the study areas, the extracting cycles used were 2, 3, $4,5,6$, and 7 ; the ethanol/bran ratios used were $8,9,10,11$, 12 , and $13 \mathrm{~mL} / \mathrm{g}$; the extracting times used were $10,20,30$, 40,50 , and $60 \mathrm{~min}$; and the temperatures used were 35, 45, 55,65 , and $75^{\circ} \mathrm{C}$. To process, when one variable was pared, the other variables were kept fixed as follows: temperature $\left(55^{\circ} \mathrm{C}\right)$, time $(30 \mathrm{~min})$, the ethanol/bran ratio $(10 \mathrm{~mL} / \mathrm{g})$, and extracting cycles (4).

2.2.2. Modelling Design. The study area defined from the single-factor experimental design (Table 1) was applied in a three-level four-variable Box-Behnken design (BBD) to minimize fibers extraction yield. The four independent variables considered in this study were numbers of extracting cycles $\left(x_{1}\right)$, ethanol/residue $\left(x_{2}\right)$, times $\left(x_{3}\right)$, and temperature $\left(x_{4}\right)$. The extraction yield was selected as the response. 29 experimental runs were randomly used to minimize the effects of unpredicted variability in the observed responses. Five replicates (except numbers 25 29) at the center of the design were used to allow the estimation of the pure error sum of squares. The variables were coded according to the following equation:

$$
x_{i}=\frac{X_{i}-X_{0}}{\Delta X_{i}}, \quad i=1,2,
$$

where $x_{i}$ is the (dimensionless) coded value of the variable $X_{i}$, $X_{0}$ is the value of $X_{i}$ at the central point, and $\Delta X_{i}$ is the step 


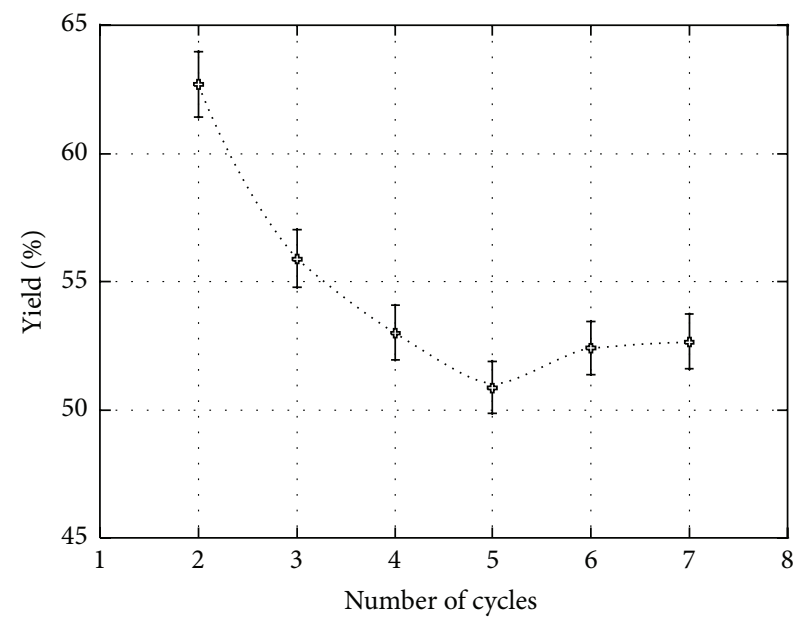

(a)

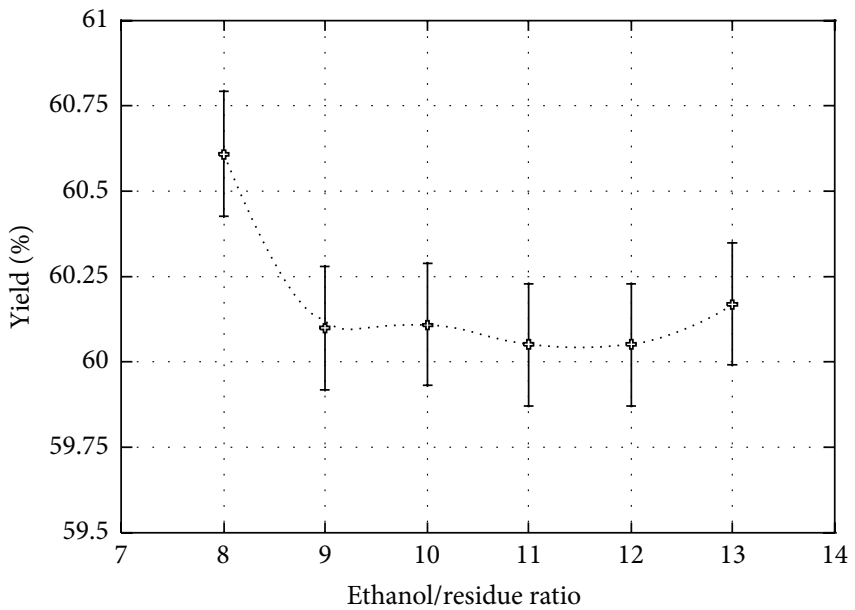

(b)

FIGURE 1: Effect of extraction cycles (a) and ethanol/bran ratio (b) on the yield of extraction of fibers from sorghum bran.

change. The following second-degree polynomial equation was used to depict the extraction process:

$$
Y=\beta_{0}+\sum_{i=1}^{4} \beta_{i} x_{i}+\sum_{i=1}^{4} \beta_{i i} x_{i}^{2}+\sum_{i \neq j=1}^{3} \sum_{j=1}^{4} \beta_{i j} x_{i} x_{j}+\varepsilon
$$

where $Y$ is the response (extraction yield in $\%), \beta_{0}, \beta_{i}$, $\beta_{i i}$, and $\beta_{i j}$ are constant coefficients of the intercept, linear, quadratic, and interaction terms, respectively, $x_{i}$ and $x_{j}$ are coded independent variables, and $\varepsilon$ represents the residue $[29,30]$.

Stepwise regression is a semiautomated process of building a model by successively adding (forward) or removing (backward) variables based solely on the $t$-statistics $(F=t$ squared) of their estimated coefficients [31]. The Backward approach of the stepwise regression option in Statgraphics was used to successively remove the variable with the smallest $F$-to-remove statistic, provided that this is less than the threshold value for $F$-to-remove, that is, eliminating nonsignificant terms from the full model in order to fine-tune it $[31,32]$. The model obtained from the above design was used by the path of steepest descent procedure to move towards the vicinity of optimum region. The experimental yield obtained from the BBD model was compared with the path of steepest descent experimental yields.

2.3. Statistical Analyses. Three replicates of the data were performed and the data was expressed as means and standard error (SE). The path of steepest descent and the BBD regression analysis were conducted using Statgraphics Plus 5.1 software to estimate the optima from the independent variables. The quality of the fitted polynomial model equation was assessed by the lack of fit test, the coefficient of determination $\left(R^{2}\right)$ and the adjusted coefficient of determination (Adj. $R^{2}$ ). The significance of the regression coefficients was checked by $F$-test using $P=0.05$ the significance level.

\section{Results and Discussion}

\subsection{Effects of Independent Variables on the Extraction of Fibers from Sorghum Bran}

3.1.1. Effect of Extraction Cycles. The extraction experiment shows a two-phase process (Figure 1(a)): the first phase is between 2 and 5 cycles, with the extraction yields decreasing sharply from $62.7 \%$ to $51.21 \%(P<0.05)$. The second phase (5 to 7 cycles) provides comparable yield values $(51.21 \%$ and $52.64 \%$ ). This second phase is explained by the establishment of a dynamic equilibrium where no more exchange is possible between the two compartments (Figure 1(a)). Thus, an extraction cycles range of 5-7 was adopted for the BBD model.

3.1.2. Effect of the Ratio. As seen from Figure 1(b), the yield declined from 60.61 to $60.11 \%(P<0.05)$ when the ratio went up from 8 to $10 \mathrm{~mL} / \mathrm{g}$. The same dynamic equilibrium is observed, as previously, between 10 and $12 \mathrm{~mL} / \mathrm{g}$ with an average yield of $60.05 \%(P>0.05)$. The yield slightly increased from 60.05 to $60.17 \%(P<0.05)$ between 12 and $13 \mathrm{~mL} / \mathrm{g}$. Thus, the range of ethanol to sample ratio of $10-$ $12 \mathrm{~mL} / \mathrm{g}$ was used in the BBD model.

3.1.3. Effect of Time. The kinetics of extraction of fibers from sorghum bran indicates that the fibers extraction process exhibits two distinctive phases (Figure 2(a)). During the first phase, the extraction yield drops sharply from 60.54 to $51.03 \%$ $(P<0.05)$ when the time moves from 10 to 40 minutes. During the second phase, the extraction yield reaches a stationary state with an average of $50.80 \%$ between 40 and 60 minutes. This last range was used in the BBD model.

3.1.4. Effect of Temperature. During the definition of temperature range, it was observed that the yield diminishes from 58.23 to $54.85 \%$ when the temperature rises from 35 to $45^{\circ} \mathrm{C}$ 


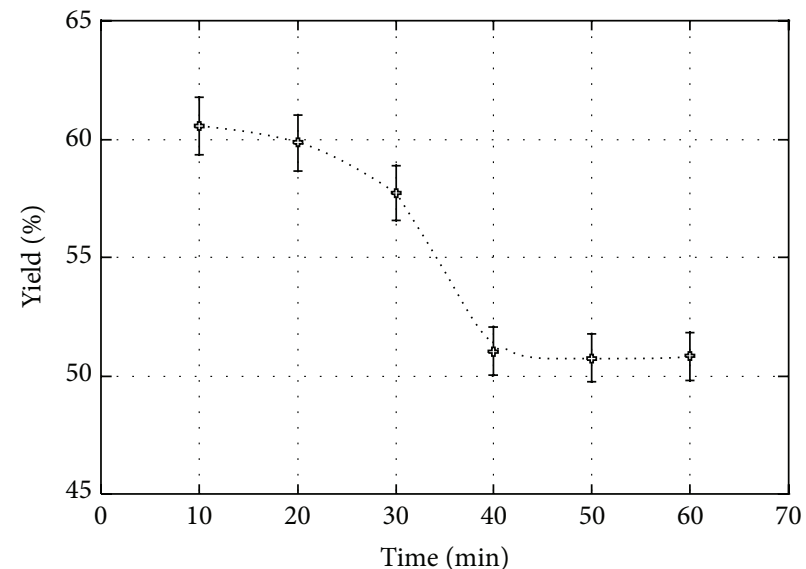

(a)

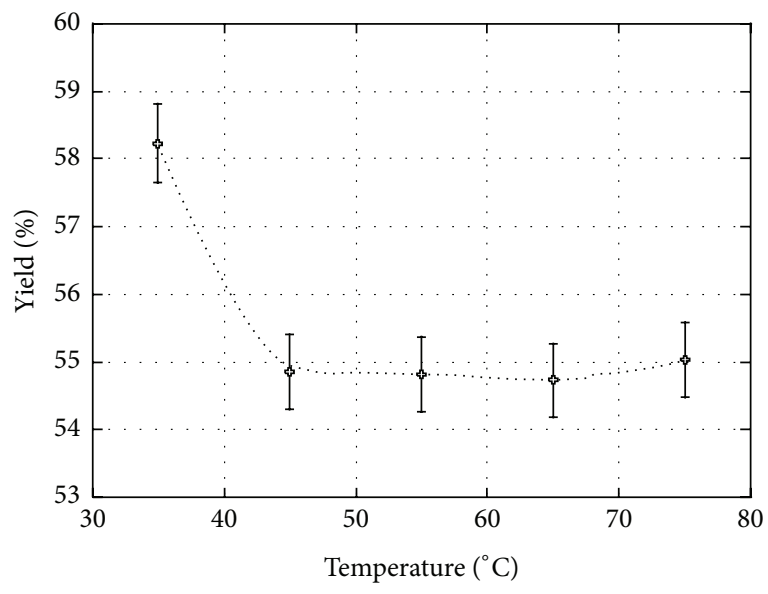

(b)

FIGURE 2: Effect of extraction time (a) and temperature (b) on the yield of extraction of fibers from sorghum bran.

$(P<0.05)$. It also reached a dynamic equilibrium that is located between 45 and $65^{\circ} \mathrm{C}$ with an average yield of $54.82 \%$ (Figure 2(b)). The range $45-65^{\circ} \mathrm{C}$ was adopted for the $\mathrm{BBD}$ model. The study intervals for the optimization process using the BBD model are compiled in Table 1.

3.2. Modeling Process. The twenty-nine experimental runs for the optimization of the four individual variables in the BBD are shown in Table 2. The percentage yield ranged from 34.68 to $58.52 \%$.

A regression analysis (Table 3) was carried out to fit a statistical model to the experimental data. After dropping nonsignificant terms from the full second-order model using stepwise regression, the yield of fibers extraction from sorghum bran can be expressed by the following refined second-order polynomial equation in terms of coded values:

$$
\begin{aligned}
\text { Yield }(\%)= & 44.54-6.37 \times x_{1}-1.81 \times x_{3}+1.96 \times x_{1}^{2} \\
& -3.66 \times x_{1} \times x_{2}+2.78 \times x_{2}^{2}+3.19 \times x_{2} \\
& \times x_{3}-3.90 \times x_{2} \times x_{4}-2.25 \times x_{3}^{2},
\end{aligned}
$$

where $x_{1}, x_{2}, x_{3}$, and $x_{4}$ were the coded values of the independent variables: number of cycles, ratio of ethanol to bran, time, and temperature, respectively.

The analysis of variance (ANOVA) (Table 3) showed that this regression model was extremely significant $(P<$ 0.00001 ). A model with $P$ value less than 0.001 is highly significant [33]. The lack of fit test measures the failure of the model to represent the data in the experimental domain at points which are not included in the regression. As shown in Table 3, $F$-value and $P$ value of the lack of fit test were 2.94 and 0.16 , respectively, which implies it was not significant and indicates that the model equation was adequate for predicting the extraction of fibers from sorghum bran. The fitness of the model was further confirmed by a satisfactory value of the determination coefficient, which was calculated to be 0.90 , indicating that $90 \%$ of the variability in the response could be predicted by the model. The value of the adjusted

\begin{tabular}{|c|c|c|c|c|c|}
\hline Number & $x_{1}$ & $x_{2}$ & $x_{3}$ & $x_{4}$ & Yield (\%) \\
\hline 1 & 0 & 0 & 1 & -1 & 38.14 \\
\hline 2 & 0 & 0 & -1 & 1 & 41.08 \\
\hline 3 & 1 & 1 & 0 & 0 & 38.78 \\
\hline 4 & 1 & 0 & -1 & 0 & 43.70 \\
\hline 5 & -1 & 0 & -1 & 0 & 52.58 \\
\hline 6 & 0 & 0 & 0 & 0 & 42.90 \\
\hline 7 & -1 & 0 & 0 & 1 & 53.36 \\
\hline 8 & 0 & -1 & 1 & 0 & 39.86 \\
\hline 9 & -1 & 0 & 0 & -1 & 53.32 \\
\hline 10 & 1 & 0 & 0 & 1 & 42.62 \\
\hline 11 & 0 & 0 & 0 & 0 & 42.88 \\
\hline 12 & 0 & 0 & 1 & 1 & 41.02 \\
\hline 13 & -1 & -1 & 0 & 0 & 49.42 \\
\hline 14 & 0 & 1 & 0 & -1 & 50.70 \\
\hline 15 & 0 & 1 & -1 & 0 & 43.74 \\
\hline 16 & -1 & 1 & 0 & 0 & 58.52 \\
\hline 17 & 0 & 1 & 1 & 0 & 47.58 \\
\hline 18 & 0 & 1 & 0 & 1 & 45.68 \\
\hline 19 & 0 & 0 & -1 & -1 & 44.26 \\
\hline 20 & -1 & 0 & 1 & 0 & 51.10 \\
\hline 21 & 1 & 0 & 1 & 0 & 34.68 \\
\hline 22 & 0 & -1 & -1 & 0 & 48.76 \\
\hline 23 & 1 & 0 & 0 & -1 & 37.76 \\
\hline 24 & 0 & -1 & 0 & -1 & 44.42 \\
\hline 25 & 0 & -1 & 0 & 1 & 54.98 \\
\hline 26 & 0 & 0 & 0 & 0 & 44.78 \\
\hline 27 & 1 & -1 & 0 & 0 & 44.30 \\
\hline 28 & 0 & 0 & 0 & 0 & 45.40 \\
\hline 29 & 0 & 0 & 0 & 0 & 45.30 \\
\hline
\end{tabular}

TABLE 2: BBD matrix for the four variables and the observed responses.

determination coefficient (adjusted $R^{2}=0.85$ ) also confirmed that the model was highly robust. 
TABLE 3: ANOVA of fitted quadratic polynomial model of the extraction yield.

\begin{tabular}{|c|c|c|c|c|c|}
\hline Source & Sum of squares & Degree of freedom & Mean squares & $F$-ratio & $P$ value \\
\hline Model & 808.31 & 8 & 101.04 & 21.63 & $0.0000^{*}$ \\
\hline$x_{1}:$ cycles & 487.18 & 1 & 487.18 & 304.24 & $0.0001^{*}$ \\
\hline$x_{2}:$ ratio & 0.89 & 1 & 0.89 & 0.55 & 0.4984 \\
\hline$x_{3}$ : Time & 39.39 & 1 & 39.39 & 24.60 & $0.0077^{*}$ \\
\hline$x_{4}$ : temperature & 8.57 & 1 & 8.57 & 5.35 & 0.0817 \\
\hline$x_{1}^{2}$ & 27.08 & 1 & 27.08 & 16.91 & $0.0147^{*}$ \\
\hline$x_{1} x_{2}$ & 53.44 & 1 & 53.45 & 33.37 & $0.0045^{*}$ \\
\hline$x_{1} x_{3}$ & 14.21 & 1 & 14.21 & 8.88 & $0.0408^{*}$ \\
\hline$x_{1} x_{4}$ & 5.81 & 1 & 5.81 & 3.63 & 0.1296 \\
\hline$x_{2}^{2}$ & 53.36 & 1 & 53.36 & 33.32 & $0.0045^{*}$ \\
\hline$x_{2} x_{3}$ & 40.58 & 1 & 40.58 & 25.34 & $0.0073^{*}$ \\
\hline$x_{2} x_{4}$ & 60.68 & 1 & 60.68 & 37.90 & $0.0035^{*}$ \\
\hline$x_{3}^{2}$ & 30.31 & 1 & 30.31 & 18.93 & $0.0121^{*}$ \\
\hline$x_{3} x_{4}$ & 9.18 & 1 & 9.18 & 5.73 & 0.0748 \\
\hline$x_{4}^{2}$ & 1.27 & 1 & 1.27 & 0.80 & 0.4228 \\
\hline Lack of fit & 47.09 & 10 & 4.71 & 2.94 & 0.1550 \\
\hline Residue & 93.43 & 20 & 4.67 & & \\
\hline Pure error & 6.41 & 4 & 1.60 & & \\
\hline Cor Total & 901.74 & 28 & & & \\
\hline
\end{tabular}

${ }^{*}$ Significant at 0.05 .

A $R^{2}$ greater than 0.75 indicates that the aptness of the model is significant [33]. The optimization of multilevel ethanol leaching process of porang flour (Amorphophallus muelleri) using RSM had a value $R^{2}=0.9505$, Adj. $R^{2}$ of 0.9060 to improve the glucomannan content and $R^{2}=$ 0.9505 , Adj. $R^{2}=0.7298$ to reduce the calcium oxalate content with lack of fit $(P>0.05)$ which showed that this model was significant [33]. The optimization of the extract of polysaccharides from the fruit of Capparis spinosa by BBD had a value $R^{2}=0.9460$ and lack of fit $(P>0.05)$, indicating that the model could explain $94.60 \%$ of the response value changes and only $5.40 \%$ of the total variations was not explained by the model and showed that quadratic model was significant [27]. Claver et al. [34] research on optimization of extraction of polysaccharides from Chinese malted sorghum using BBD has a value $R^{2}=0.997$ and adjusted $R^{2}=0.994$, which was reasonably close to 1 and implied that only less than $1.0 \%$ of the total variations were not explained by the model. The curve shape of the response surface and the oval features of the lines in the contour plot (Figure 3) confirm the fact that a second-degree polynomial model equation is appropriate to describe the behavior of the extraction system.

As shown in Table 3, among the significant terms $(P<$ $0.05)$, the variable with the highest effect was the number of cycles $\left(x_{1}\right)$, which was extremely significant with $P<0.0001$. In fact, the extraction solvent (ethanol) would increase osmotic exchanges between the plant substrate and the aqueous phase immersion. Ji et al. [35] showed that the number of cycles was the most important factor $(P<0.0001)$ during the optimization of the extraction of polysaccharides from fruit Capparis spinosa using RSM. The multiple leaching processes allowed gradual removal of nonfibrous compounds and thus enriching the residue in fibers. Compounds dissolved in ethanol are resin, fat, fatty acid, carbohydrate, starch, protein, oxalate, calcium oxalate, ash, and others organic compounds $[36,37]$. The time $\left(x_{3}\right)$ appears as the second most important linear factor. Claver et al. [34] showed that the time was the second important factor after ultrasonic power during the optimization of the extraction of polysaccharides from malted sorghum using RSM.

\subsection{Optimization of Extracting Conditions and Validation of the Model}

3.3.1. Optimization and Verification of the Model. The optimum conditions of fibers extraction from sorghum bran predicted by the regression model were as follows: ethanol/bran ratio $\left(11.8 \mathrm{~mL} \cdot \mathrm{g}^{-1}\right)$, time $(60 \mathrm{~min})$, temperature $\left(65^{\circ} \mathrm{C}\right)$, and 7 extraction cycles. These conditions were tested and compared to the predicted optimal value to measure the robustness of the model. The observed optimal yield is $35.52 \pm 0.27 \%$ ( $n=$ 3 ) which is in close agreement with the predicted optimal value of the model, $34.36 \%(P>0.05)$. The results of analysis confirmed that the response model was suitable to reflect the expected optimum and (4) was satisfactory and accurate. The amount of bran fibers obtained during this process is close to the range of total dietary fiber content in sorghum bran fraction (36-50\%) reported by Rooney et al. [17].

3.3.2. Tests of Validity. In order to confirm that the optimal conditions generated by the model from the study region were the ideal ones, the path of steepest descent was also used to search for another study area that could produce a lower 

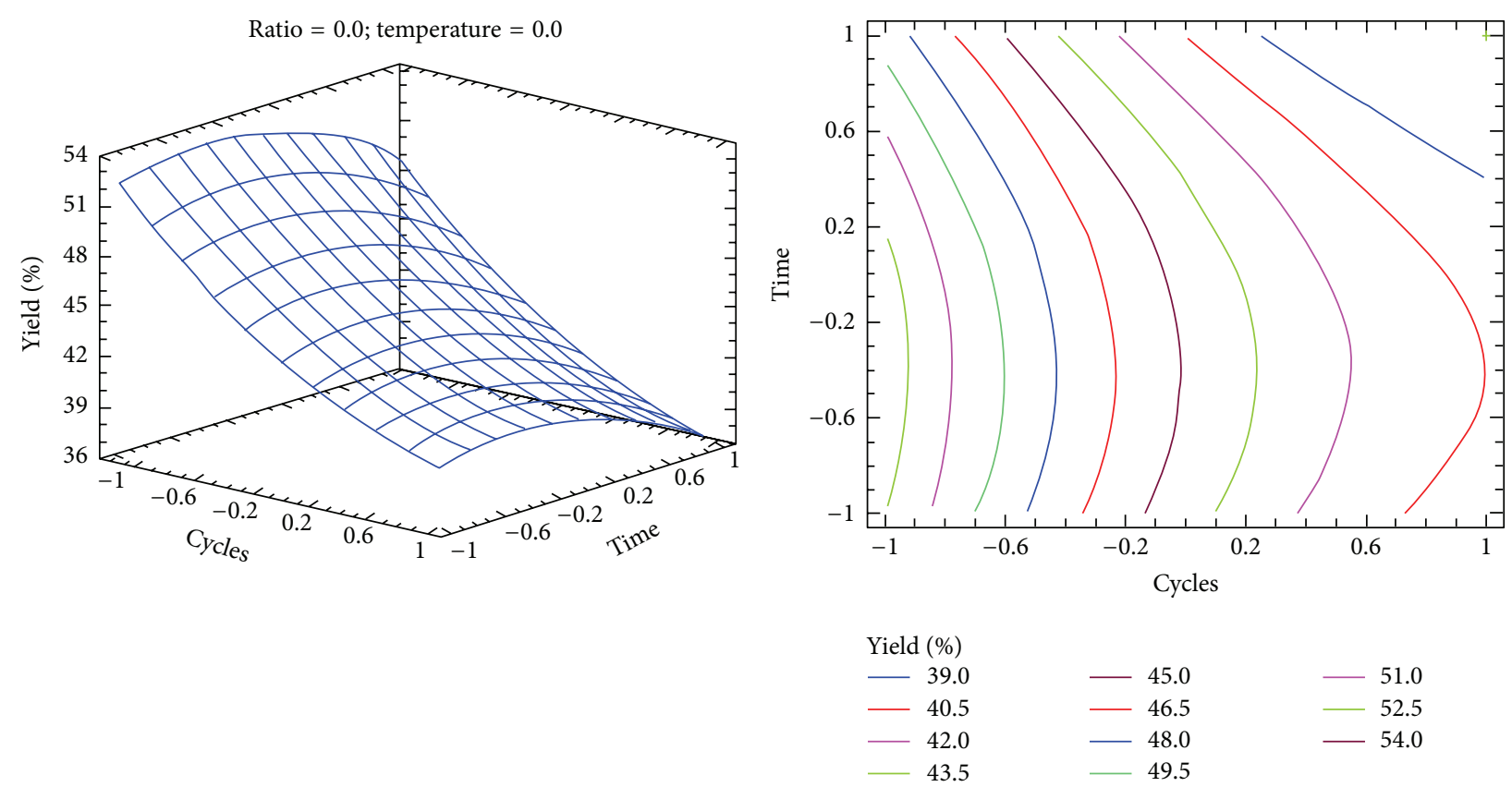

FIGURE 3: Response surface plots (3D) and contour plots (2D) showing the effects of the variables: number of cycles and time. On the contour plots (2D), the extraction yield increases from right to the left (39.0 to $54 \%)$.

predicted optimal yield with different conditions. By using this statistical approach, we were able to identify specific conditions bound to their corresponding extraction yield by executing factor variations. Table 4 indicates the variation of extraction cycles $\left(\mathrm{C}_{1}-\mathrm{C}_{5}\right)$ and time $\left(\mathrm{C}_{6}-\mathrm{C}_{10}\right)$ generated by the path of steepest descent. From these conditions, only two combinations of factors $\left(\mathrm{C}_{2}\right.$ and $\left.\mathrm{C}_{7}\right)$ appear to be realizable due to their feasibility and lower predicted yield.

After decoding and experimenting at these conditions, the first combination $\mathrm{C}_{2}\left(12 \mathrm{~mL} / \mathrm{g}, 60 \mathrm{~min}, 65^{\circ} \mathrm{C}\right.$, and 8 cycles $)$ resulted in an observed yield of $35.50 \pm 0.30 \%(n=3)$, which is not statistically different from the observed optimal yield of the BBD model (35.52\%). The second combination $\mathrm{C}_{7}$ $\left(11 \mathrm{~mL} / \mathrm{g}, 70 \mathrm{~min}, 55^{\circ} \mathrm{C}\right.$, and 8 cycles) resulted in an observed yield of $39.90 \pm 0.11 \%(n=3)$ which is higher than the BBD observed optimal yield $(P<0.05)$. Compared to the first combination generated by the path of steepest descent $\left(\mathrm{C}_{2}\right)$, the BBD model conditions were more economical with a smaller number of cycles and an ethanol ratio. The optimal conditions from the BBD appear to be the best in bran fibers extraction.

\section{Conclusion}

The study region to optimize the extraction of fibers from sorghum bran was evaluated using the Box-Behnken design and the path of steepest descent. The predicted Box-Behnken conditions were found to be realistic and suitable in terms of overall duration (lower number of cycles) and the small amount of ethanol used compared to the path of steepest descent conditions. Based on the BBD model, the optimal extraction conditions were determined to be as follows: 7
TABLE 4: Path of steepest descent conditions generated by variation of extracting cycles $\left(\mathrm{C}_{1}-\mathrm{C}_{5}\right)$ and time $\left(\mathrm{C}_{6}-\mathrm{C}_{10}\right)$.

\begin{tabular}{|c|c|c|c|c|c|}
\hline \multirow{2}{*}{ Conditions } & \multicolumn{4}{|c|}{ Variables } & \multirow{2}{*}{$\begin{array}{l}\text { Predicted } \\
\text { yield (\%) }\end{array}$} \\
\hline & Cycles & Ratio & Time & Temperature & \\
\hline $\mathrm{C}_{0}$ & 0.0 & 0.0 & 0.0 & 0.0 & 44.54 \\
\hline $\mathrm{C}_{1}$ & 1.0 & 0.15 & 0.7 & 0.1 & 37.65 \\
\hline $\mathrm{C}_{2}$ & 2.0 & 0.98 & 1.0 & 0.9 & 30.68 \\
\hline $\mathrm{C}_{3}$ & 3.0 & 1.6 & 7.9 & 4.4 & -108.91 \\
\hline $\mathrm{C}_{4}$ & 4.0 & 5.0 & -4.3 & 5.0 & -150.64 \\
\hline $\mathrm{C}_{5}$ & 5.0 & 7.3 & -8.4 & 7.2 & -464.56 \\
\hline $\mathrm{C}_{6}$ & 1.2 & 0.2 & 1.0 & 0.1 & 35.50 \\
\hline $\mathrm{C}_{7}$ & 1.4 & 0.1 & 2.0 & 0.2 & 26.96 \\
\hline $\mathrm{C}_{8}$ & 1.5 & 0.0 & 3.0 & 0.2 & 13.65 \\
\hline $\mathrm{C}_{9}$ & 1.5 & -0.3 & 4.0 & 0.2 & -5.34 \\
\hline $\mathrm{C}_{10}$ & 1.4 & -0.5 & 5.0 & 0.1 & -30.47 \\
\hline
\end{tabular}

cycles, $11.8 \mathrm{~mL} \cdot \mathrm{g}^{-1}$ of ethanol/bran ratio, $60 \mathrm{~min}$, and $65^{\circ} \mathrm{C}$. Under these optimum conditions, the observed minimal yield was $35.52 \%$, in close agreement with the predicted minimal value of the model $(34.36 \%)$. This residue can therefore be optimally extracted from sorghum bran and used as a source of dietary fibers to reduce environmental pollution due to sorghum byproducts.

\section{Conflict of Interests}

The authors declare that there is no conflict of interests concerning the publication of this paper. 


\section{References}

[1] J. W. Anderson, D. A. Deakins, T. L. Floore, B. M. Smith, and S. E. Whitis, "Dietary fiber and coronary heart disease," Critical Reviews in Food Science and Nutrition, vol. 29, no. 2, pp. 95-147, 1990.

[2] D. T. Gordon, D. Stoops, and V. Ratliff, "Dietary fiber and mineral nutrition," in Dietary Fiber in Health \& Disease, D. Kritchevsky and C. Bonfield, Eds., Eagan Press, St. Paul, Minn, USA, 1995.

[3] W. H. Ling, "Diet and colonic microflora interaction in colorectal cancer," Nutrition Research, vol. 15, no. 3, pp. 439-454, 1995.

[4] D. Lairon, N. Arnault, S. Bertrais et al., "Dietary fiber intake and risk factors for cardiovascular disease in French adults," American Journal of Clinical Nutrition, vol. 82, no. 6, pp. 11851194, 2005.

[5] B. Hiller, W. Schlörmann, M. Glei, and M. G. Lindhauer, "Comparative study of colorectal health related compounds in different types of bread: analysis of bread samples pre and post digestion in a batch fermentation model of the human intestine," Food Chemistry, vol. 125, no. 4, pp. 1202-1212, 2011.

[6] J. L. Buttriss and C. S. Stokes, "Dietary fibre and health: an overview," Nutrition Bulletin, vol. 33, no. 3, pp. 186-200, 2008.

[7] A. M. Nelson, "Defining high-fiber ingredient terminology," in High-Fiber Ingredients, A. M. Nelson, Ed., pp. 1-28, Eagan Press, Saint Paul, Minn, USA, 2002.

[8] FAOSTAT, "Database of the Food and Agriculture Organization of the United Nations," 2012, http://faostat.fao.org/ site/291/default.aspx.

[9] J. Taylor and J. Dewar, "Fermented products: beverages and porridges," in Sorghum: Origin, History, Technology and Production, C. Wayne Smith and R. A. Frederiksen, Eds., pp. 751-795, John Wiley \& Sons, New York, NY, USA, 2000.

[10] A. Kumar, Industrial Pollution \& Management, S.B. Nangia for APH Publishing Cooperation, 2004.

[11] J. M. Awika, C. M. McDonough, and L. W. Rooney, "Decorticating sorghum to concentrate healthy phytochemicals," Journal of Agricultural and Food Chemistry, vol. 53, no. 16, pp. 6230-6234, 2005.

[12] J. M. Awika, L. W. Rooney, and R. D. Waniska, "Anthocyanins from black sorghum and their antioxidant properties," Food Chemistry, vol. 90, no. 1-2, pp. 293-301, 2005.

[13] J. M. Awika, L. W. Rooney, and R. D. Waniska, "Properties of 3deoxyanthocyanins from sorghum," Journal of Agricultural and Food Chemistry, vol. 52, no. 14, pp. 4388-4394, 2004.

[14] R. D. Waniska, J. H. Poe, and R. Bandyopadhyay, "Effects of growth conditions on grain molding and phenols in sorghum caryopsis," Journal of Cereal Science, vol. 10, no. 3, pp. 217-225, 1989.

[15] V. Singh, R. A. Moreau, and K. B. Hicks, "Yield and phytosterol composition of oil extracted from grain sorghum and its wetmilled fractions," Cereal Chemistry, vol. 80, no. 2, pp. 126-129, 2003.

[16] K. T. Hwang, C. L. Weller, S. L. Cuppett, and M. A. Hanna, "Policosanol contents and composition of grain sorghum kernels and dried distillers grains," Cereal Chemistry, vol. 81, no. 3, pp. 345349, 2004.

[17] T. K. Rooney, L. W. Rooney, and J. R. Lupton, "Physiological characteristics of sorghum millet brans in the rat model," Cereal Foods World, vol. 37, no. 10, pp. 782-786, 1992.
[18] L. A. Gordon, Utilization of sorghum brans and barley flour in bread [M.S. thesis], Texas A\&M University, College Station, Tex, USA, 2001.

[19] D. Acosta, M. Barron, M. Riaz, R. Waniska, and L. W. Rooney, "Factors affecting extrusion of white sorghum to produce whole grain snacks," in Proceedings of the AACC Annual Meeting, Portland, Ore, USA, October 2003.

[20] C. R. Rudiger, The formulation of a nutraceutical bread mix using sorghum, barley and flaxseed [M.S. thesis], Texas A\&M University, College Station, Tex, USA, 2003.

[21] R. V. Muralidhar, R. R. Chirumamila, R. Marchant, and P. Nigam, "A response surface approach for the comparison of lipase production by Candida cylindracea using two different carbon sources," Biochemical Engineering Journal, vol. 9, no. 1, pp. 17-23, 2001.

[22] J. C. Liu, S. Miao, X. C. Wen, and Y. X. Sun, "Optimization of polysaccharides ( $\mathrm{ABP}$ ) extraction from the fruiting bodies of Agaricus blazei Murill using response surface methodology (RSM)," Carbohydrate Polymers, vol. 78, no. 4, pp. 704-709, 2009.

[23] Y.-X. Sun, J.-C. Liu, and J. F. Kennedy, "Extraction optimization of antioxidant polysaccharides from the fruiting bodies of Chroogomphis rutilus(Schaeff.: Fr.) O.K. Miller by Box-Behnken statistical design," Carbohydrate Polymers, vol. 82, no. 1, pp. 209214, 2010

[24] M. A. Verbruggen, G. Beldman, A. G. J. Voragen, and M. Hollemans, "Water-unextractable cell wall material from Sorghum: isolation and characterization," Journal of Cereal Science, vol. 17, no. 1, pp. 71-82, 1993.

[25] M. A. Verbruggen, G. Beldman, and A. G. J. Voragen, "Enzymic degradation of sorghum glucuronoarabinoxylans leading to tentative structures," Carbohydrate Research, vol. 306, no. 1-2, pp. 275-282, 1998.

[26] M. A. Verbruggen, B. A. Spronk, H. A. Schols et al., "Structures of enzymically derived oligosaccharides from sorghum glucuronoarabinoxylan," Carbohydrate Research, vol. 306, no. 12, pp. 265-274, 1998.

[27] M. A. Kabel, F. Carvalheiro, G. Garrote et al., "Hydrothermally treated xylan rich by-products yield different classes of xylooligosaccharides," Carbohydrate Polymers, vol. 50, no. 1, pp. 4756, 2002.

[28] B. B. Koubala, G. Kansci, C. Garnier, J.-F. Thibault, and M.-C. Ralet, "Physicochemical properties of dietary fibres prepared from ambarella (Spondias cytherea) and mango (Mangifera indica) peels," Food and Bioprocess Technology, vol. 6, no. 2, pp. 591-597, 2013.

[29] D. C. Montgomery, Design and Analysis of Experiments: Response Surface Method and Designs, John Wiley \& Sons, New York, NY, USA, 6th edition, 2005.

[30] N. Bradley, The response surface methodology [M.S. thesis], Department of Mathematical Sciences, Indiana University, South Bend, Ind, USA, 2007.

[31] M. A. Efroymson, "Multiple regression analysis," in Mathematical Methods for Digital Computers, A. Ralston and H. S. Wilf, Eds., Wiley, New York, NY, USA, 1960.

[32] J. Mark and M. A. Goldberg, "Multiple regression analysis and mass assessment: a review of the issues," The Appraisal Journal, pp. 89-109, 2001.

[33] A. Faridah and S. B. Widjanarko, "Optimization of multilevel ethanol leaching process of porang flour (Amorphophallus muelleri) using response surface methodology," International 
Journal on Advanced Science, Engineering and Information Technology, vol. 3, no. 2, pp. 74-80, 2013.

[34] I. P. Claver, H. Zhang, Q. Li, Z. Kexue, and H. Zhou, "Optimization of ultrasonic extraction of polysaccharides from chinese malted sorghum using response surface methodology," Pakistan Journal of Nutrition, vol. 9, no. 4, pp. 336-342, 2010.

[35] Y.-B. Ji, F. Dong, D.-B. Ma et al., "Optimizing the extraction of anti-tumor polysaccharides from the fruit of Capparis spionosa L. by response surface methodology," Molecules, vol. 17, no. 6, pp. 7323-7335, 2012.

[36] M. Shimizu and H. Shimahara, "Method of selective separationof konjac fluor from the tubers of Amorphophallus konjac," 2015, https://www.google.com/search?q=US3767424\&ie= utf-8\&oe=utf-8\#q=US3767424+pdf.

[37] E. Ramadhan and A. H. Phaza, The effect of ethanol, temperature and stage number concentration on ginger oleoresin extraction using batch [Ph.D. thesis], Technic Faculty, Diponegoro University, Semarang, Indonesia, 2007. 

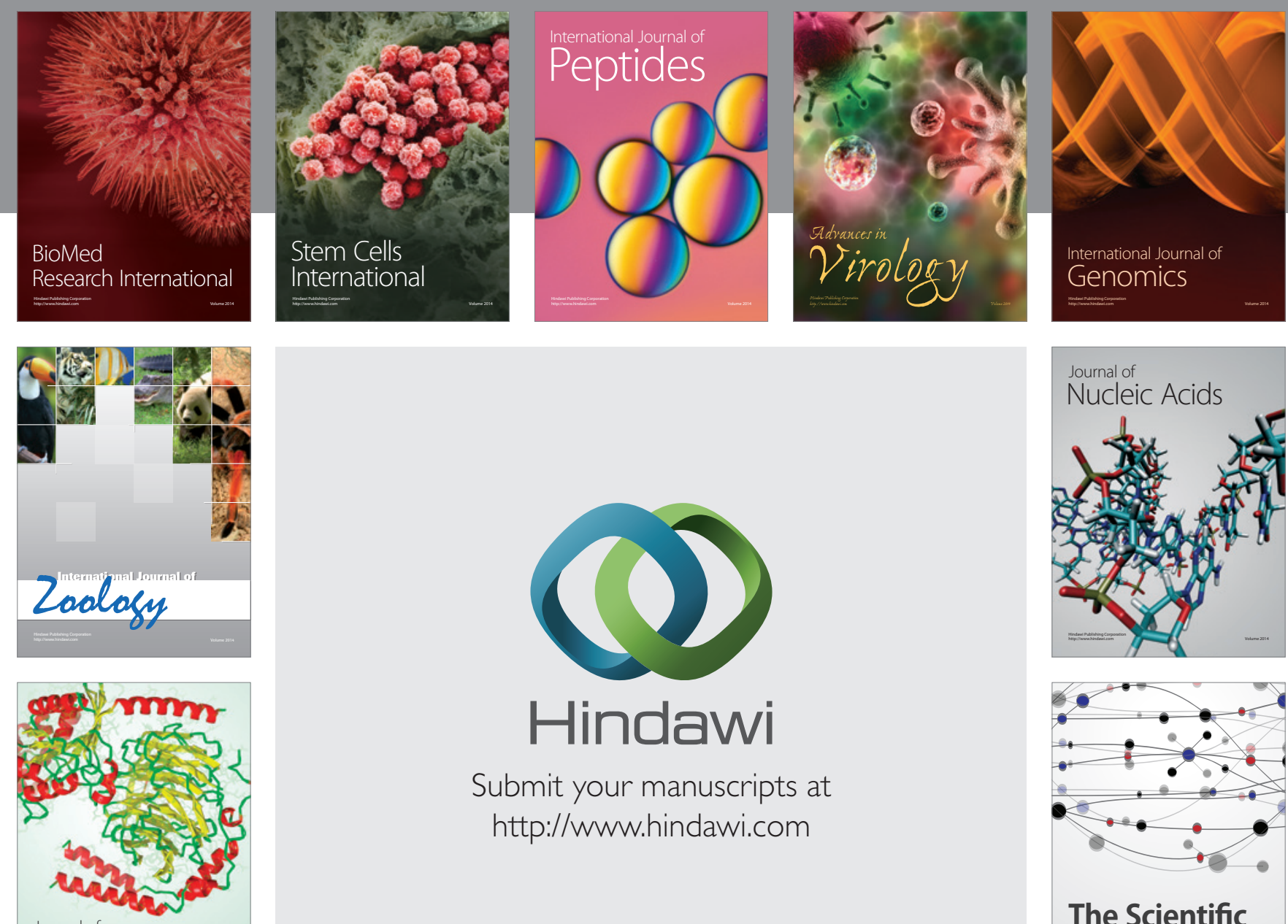

Submit your manuscripts at

http://www.hindawi.com

Journal of
Signal Transduction
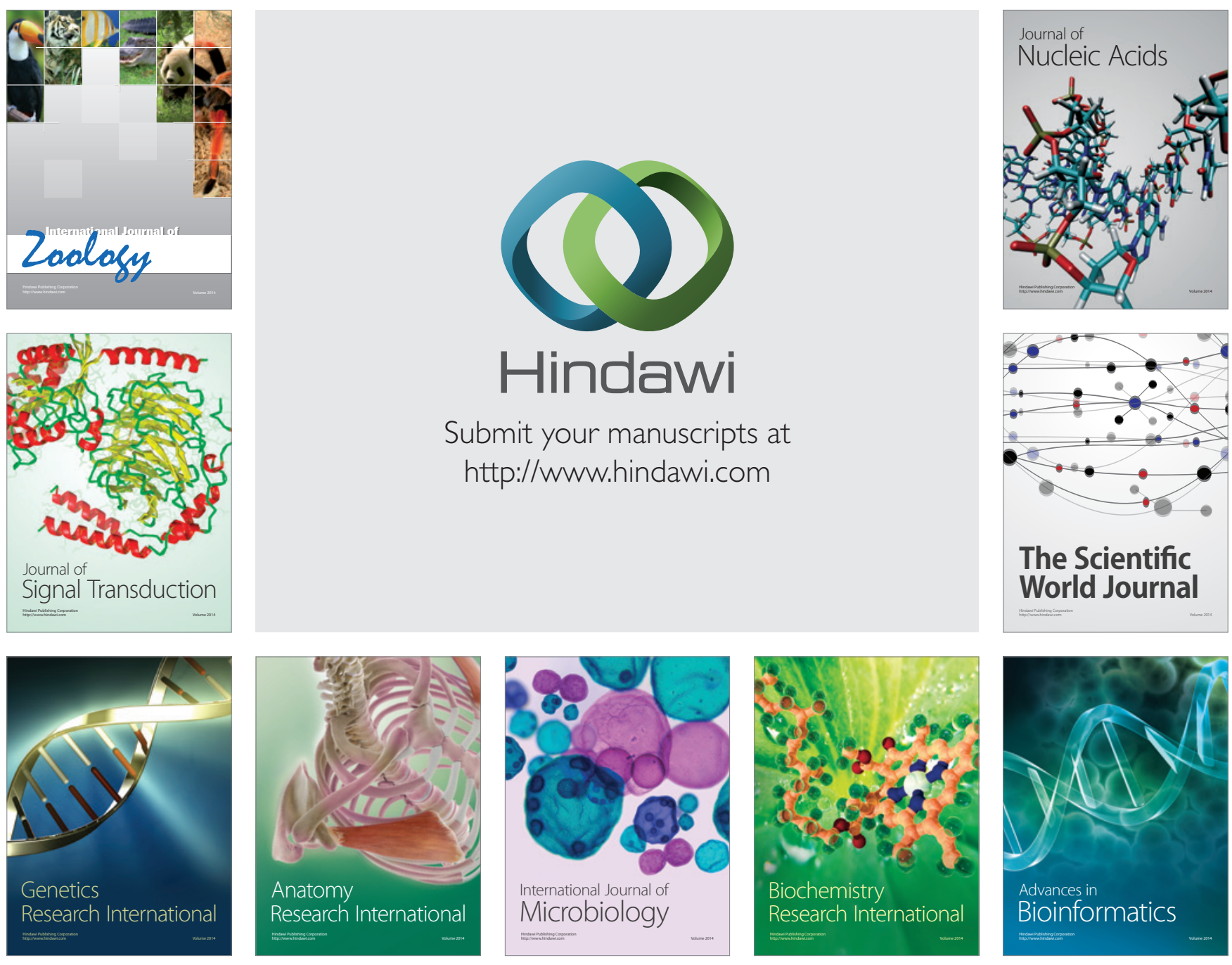

The Scientific World Journal
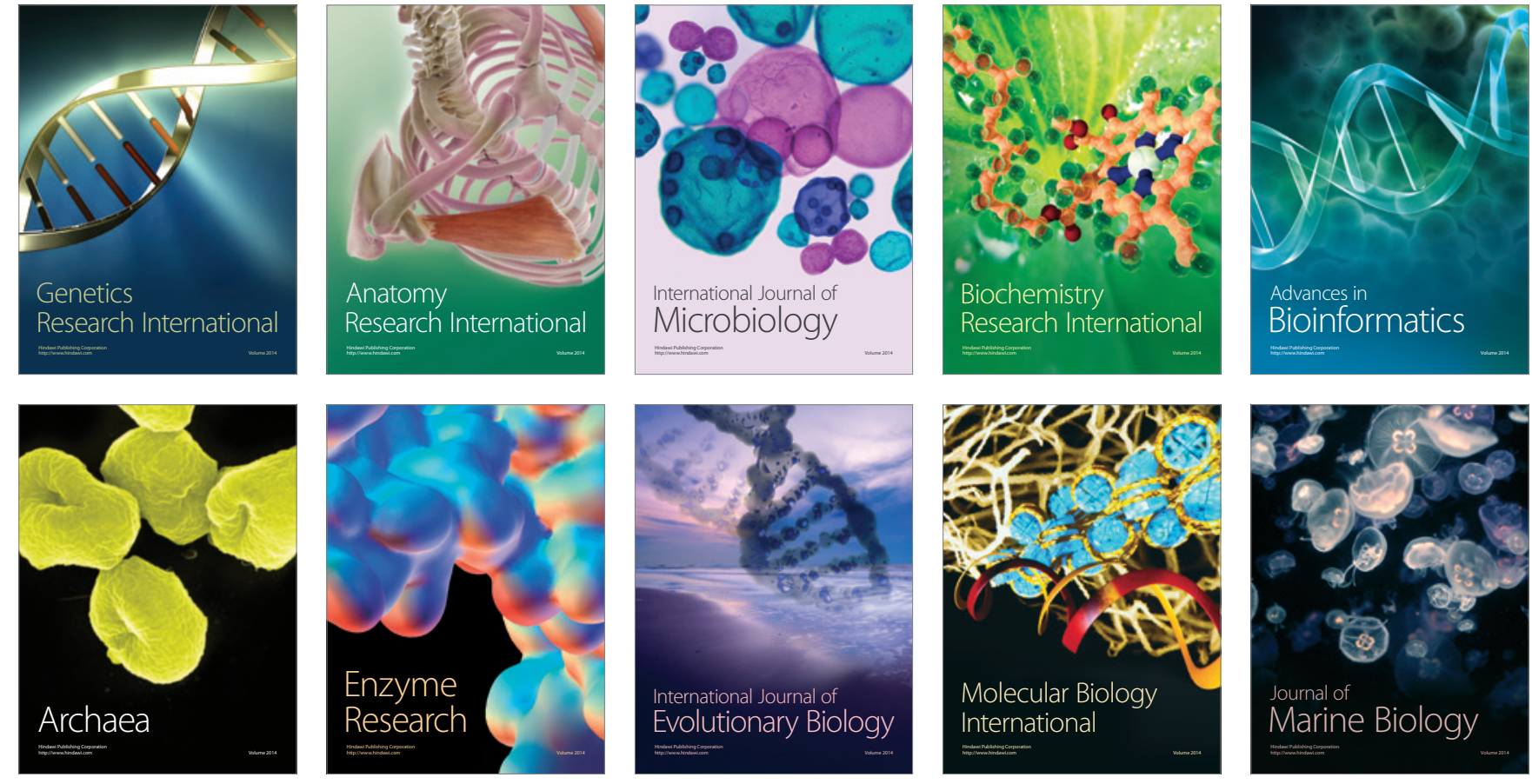